\title{
Cascading Activation Across Levels of Representation in Children's Lexical Processing
}

\section{Citation}

Huang, Yi Ting and Jesse Snedeker. 2010. Cascading activation across levels of representation in children's lexical processing. Journal of Child Language 38(3): 644-661.

\section{Published Version}

doi:10.1017/S0305000910000206

\section{Permanent link}

http://nrs.harvard.edu/urn-3:HUL.InstRepos:5345208

\section{Terms of Use}

This article was downloaded from Harvard University's DASH repository, and is made available under the terms and conditions applicable to Open Access Policy Articles, as set forth at http:// nrs.harvard.edu/urn-3:HUL.InstRepos:dash.current.terms-of-use\#OAP

\section{Share Your Story}

The Harvard community has made this article openly available.

Please share how this access benefits you. Submit a story.

\section{Accessibility}


Cascading activation across levels of representation in children's lexical processing

\author{
Yi Ting Huang ${ }^{1}$ \& Jesse Snedeker ${ }^{2}$ \\ 1. The University of North Carolina at Chapel Hill \\ 2. Harvard University
}

Acknowledgments: We would like to thank Jessica Hoy and Charlotte Distefano for their assistance in data collection and coding. We are also grateful to the children and teachers at the McGlynn Elementary School in Medford, MA for their participation in this study. This material is based upon work supported by the National Science Foundation under Grant No. 0623845. Authors address: Department of Psychology, Davie Hall CB 3270, The University of North Carolina at Chapel Hill, Chapel Hill, NC 27599. Email address: ythhuang@email.unc.edu 


\begin{abstract}
Recent work in adult psycholinguistics has demonstrated that activation of semantic representations begins long before phonological processing is complete. This incremental propagation of information across multiple levels of analysis is a hallmark of adult language processing but how does this ability develop? In two experiments, we elicit measures of incremental activation of semantic representations during word recognition in children. Fiveyear-olds were instructed to select a target $(\log s)$ while their eye-movements were measured to a competitor (key) that was semantically related to an absent phonological associate (lock). We found that like adults, children made increased looks to competitors relative to unrelated control items. However unlike adults, children continued to look at the competitor even after the target word was uniquely identified and were more likely to incorrectly select this item. Altogether, these results suggest that early lexical processing involves cascading activation but less efficient resolution of competing entries.
\end{abstract}

Keywords: word recognition, development, psycholinguistics 


\section{Introduction}

One of the hallmarks of models of adult language comprehension is the notion that linguistic information incrementally propagates across different levels of representation (MacDonald, Pearlmutter, \& Seidenberg, 1994; Trueswell \& Tanenhaus, 1994). A prime example of this is the case of word recognition (McClelland \& Elman, 1986; Marslen-Wilson, 1987; Dell, Schwartz, Martin, Saffran, \& Gagnon, 1997). By most accounts, identifying a word like $\log s$ begins with the mapping of speech sounds onto phonological representations. These phonemes then activate all lexical candidates consistent with the input and these entries in turn are linked to semantic representations of meaning (Figure 1). This description highlights two notable features of the linguistic architecture. First, since these representations are situated across multiple levels, their activation within the system is ordered. Thus some degree of phonological processing must logically precede lexical processing since the relevant phonemic features must be analyzed in order for a word to be recognized. Critically however, these linguistic procedures are not strictly sequential: Analysis at one level of representation can begin before analysis at the preceding level is complete.

\section{INSERT FIGURE 1 HERE}

A particularly persuasive illustration of this comes from a study by Yee and Sedivy (2006), demonstrating that hearing a word not only activates other words with the overlapping phonological representations but also activates the semantic associates of words in this phonological cohort. For example, Yee and Sedivy found that adults who were instructed to select a picture of logs made spurious looks to picture of a key in the display. This presumably occurred because the word logs activated absent members of its phonological cohort like lock, which led to semantic priming of related concepts like key. This short-lived activation of the 
phono-semantic competitor was time-locked to the initial $300 \mathrm{~ms}$ of ambiguity between the Target and the mediating phonological associate. Findings such as these demonstrate that adult word recognition is a characterized by an informational cascade whereby partial phonological information incrementally activates semantic representations.

But how might this ability develop? Is this informational cascade a basic architectural feature of the lexicon or is it a late-emerging capacity? To explore these questions, we looked for evidence of cascading processing in children's word recognition. Among prior developmental research, there is ample evidence that children rapidly use phonological information to restrict reference in visual forced-choice tasks (Swingley, Pinto, Fernald, 1999; Fernald, Swingley, \& Pinto, 2001; Sekerina \& Brooks, 2007). For example, 18-month-olds reliably fixate on a correct referent of a word after hearing only its onset (e.g., the /bei/ in baby, Fernald et al., 2001). Futhermore, when asked to identify a word like doggie, two-year-olds are slower to look at the referent when it is paired with a member of the same phonological cohort, like doll, than when it is paired with a non-cohort member, like tree (Swingley et al., 1999).

However, while these findings highlight rapid reference restriction in children, they do not provide clear evidence that semantic representations are invoked during this process. In particular, these tasks primarily measure looks to a displayed referent, thus they cannot rule out the possibility that these early looks are based on direct mappings between word forms and the pictures in the experimental displays. Word recognition tasks typically begin with a series of familiarization trials exposing the child to repeated pairings of the target picture (e.g., dog) with an ostensive sentence (e.g., 'That's a doggie!'). However, since the ability to identify the word in the test trials is measured by the latency to look at that same target when paired with a distractor (e.g., tree), these fixations may reflect a direct mapping that occurred between the 
phonological form and the referent during preceding familiarization phase, instead of referential processes that are mediated by the incremental activation of lexical semantics.

To directly address whether young children, like adults, rapidly transfer information across levels of representation, we need a measure of informational cascade that does not rely on looks to a displayed referent. We accomplished this by adapting the task from Yee and Sedivy (2006) for use in five-year-olds. Children in this age range are of particular interest because they are linguistically competent by most measures yet they differ from adults in many important ways. Unlike adults, most five-year-olds are functionally illiterate, have substantially smaller vocabularies, and possess limited metalinguistic awareness. Thus their experiences with language are considerably different from those of the well-educated adults that are typically studied. Furthermore, children at this age differ from adults by other cognitive measures. They have smaller memory spans (Dempster, 1981; Schneider \& Bjorklund, 1998), slower processing speed (Kail, 1991; Kail \& Salthouse, 1994), and are notoriously poor at tasks which require the inhibition of dominant responses (Piaget, 1946; Flavell, 1986; Welsh, Pennington \& Groisser, 1991; Passler, Isaac \& Hynd, 1985; Permer \& Wimmer, 1985; Hughes \& Graham, 2002).

These differences could have profound implications for the development of the language processing system. For example, resource limitations or a slower processing speed might hamper children's ability to simultaneously activate phonological and semantic representations. Similarly, poor inhibitory processing could make it more difficult for children to deactivate semantic competitors, possibly increasing the costs of incrementality. Prior research on children's sentence processing suggests that comprehension in children may be more modular or dependant on bottom-up information than comprehension in adults (Traxler, 2002; Joseph, Liversedge, Blythe, White, Gathercole, \& Rayner, 2008; Trueswell, Sekerina, Hill, \& Logrip, 
1999; Snedeker \& Trueswell, 2004; Mazzocco, 1997; Doherty, 2004; Huang \& Snedeker, in press). This is precisely the pattern we would expect if children were less incremental, resolving ambiguity at lower levels before passing information on to higher ones.

In the following experiment, adults and children were asked to select a target $\left(\log _{s}\right)$ in the presence of a competitor (key) that was semantically related to an absent phonological associate (lock). If incremental propagation of information across multiple levels of representation is a late-developing property of comprehension, we would expect children to generate few or no looks to the phono-semantic competitor. If, however, it is an inherent constraint of the architecture of the processing system, we would expect these looks to be common in children as well as adults.

\section{Experiment 1}

\subsection{Methods}

\subsubsection{Participants}

Twenty-six undergraduate students and 30 five-year-olds (ranging from 5;2 to 5;7, mean age $5 ; 5)$ participated in this study. All participants were native English speakers.

\subsubsection{Procedure and Materials}

Participants sat in front of an inclined podium divided into four quadrants, each containing a shelf where pictures could be placed (Figure 2). A camera at the center of the display was focused on the participant's face and recorded the direction of their gaze while they were

performing the task. A second camera recorded both the location of the items in the display and participants' subsequent actions. For every trial, the experimenter took out four pictures and placed them on each shelf in a pre-specified order. This presentation took approximately five 
seconds. The experimenter then played a pre-recorded utterance on a computer which instructed participants to select one of the pictures ('Pick up the logs').

\section{INSERT FIGURE 2 HERE}

We defined the Target $(\log s)$ as the picture specified by the instruction. For critical trials, the Competitor (key) was semantically related to an absent member of the Target's phonological cohort (lock). The average length of phonological ambiguity between the Target and this phonological associate was $300 \mathrm{~ms}$ and the average degree of semantic similarity between the Competitor and phonological associate was $\mathrm{M}=.18(\mathrm{SD}=.20) .{ }^{1} \quad$ To avoid other potential sources of priming, the Competitor was selected to be both phonologically unrelated (i.e., not sharing in onset cluster) and semantically unrelated to the Target $(\mathrm{M}<.01)$. For control trials, the Competitor was replaced with an unrelated Control item (carrot) that was phonologically and semantically unrelated to the Target as well as its phonological associate (both M's<.01). For each display, the Target and Competitor/Control items were paired with two additional Distractors that were selected based on the same criteria as the Control item (whale and shirt).

Sixteen base triplets consisting of a Target, Competitor, and Control item were used to generate two versions of each item (Critical vs. Control trial) which appeared in two presentation lists such that each list contained eight items in each condition and that each base item appeared just once in every list (Appendix A). Every item that appeared as a Control item on one list

\footnotetext{
${ }^{1}$ The degree of semantic similarity was based on measures of cue-to-target strength from Appendix A of Nelson, McEvoy, and Schreiber (1998). These are standardized norms calculated by dividing the proportion of participants who produce a particular target in the presence of the cue word. However, the frequency of production among many of these unrelated pairs was so low that the corresponding proportions were often not listed in the database. Thus to ensure that our critical items were equally unrelated to the Target, we gathered semantic relatedness ratings from a separate group of 12 participants. These judgments were conducted on a seven-point scale $(1=$ very unrelated, $7=$ very related) and confirmed that there were no differences in the degree of relatedness between Target-Competitor pairs $(\mathrm{M}=1.67, \mathrm{SD}=.57)$ and Target-Control pairs $(\mathrm{M}=1.50, \mathrm{SD}=.40, \mathrm{p}>.40)$.
} 
appeared as a Competitor on the other list, ensuring that any differences between the two item types could not be due to differences in the perceptual salience of a particular item. Colored pictures of these items were pretested with a separate group of participants to ensure that they spontaneously named the images with the word we intended to use.

Eye-movements were coded, frame-by-frame, from the videotape of the participants face by a research assistant who was blind to the location of each. Each recorded trial began at the onset of the instruction and ended with completion of the corresponding action. Each change in direction of gaze was coded as towards one of the quadrants, at the center, or missing due to looks away from the display or blinking. Twenty-five percent of the trials were checked by second coder who confirmed the fixation locations for $96.1 \%$ of the coded frames. This method of measuring eye-movements has produced data equivalent to that collected using head-mounted eye-tracking (see Appendix D of Snedeker \& Trueswell, 2004).

\subsection{Results and Discussion}

Figures 3 and 4 illustrate that Target looks for both adults and children were initially around chance prior to the onset of the critical word and rapidly increased following this target word. To assess the degree of phono-semantic priming, we calculated the total looking time to the Competitor or Control as a proportion of looking time to all four cards. Each time window began and ended $200 \mathrm{~ms}$ after the relevant marker in the speech stream to account for the time needed to program saccadic eye-movements (Matin, Shao, \& Boff, 1993) and was analyzed with both subjects and items ANOVAs.

\section{INSERT FIGURES 3 \& 4 HERE}

We first examine fixations during a baseline period prior to the onset of the target word ('Pick up the') and found no difference in the looks to the Competitor and Control pictures in 
either adults ( $31 \%$ vs. $29 \%$ ) or children ( $28 \%$ vs. $24 \%$; all p's >.15). However, following the onset of the target word ('logs'), looks in these conditions began to diverge. To establish when differences emerged, we calculated the proportion of fixations to the Competitor and Control pictures for $100 \mathrm{~ms}$ intervals beginning from the onset of the target word and continuing until $1000 \mathrm{~ms}$ later. Each of the eight time windows $(200 \mathrm{~ms}-900 \mathrm{~ms})$ is defined by the period from the labeled time point to the frame prior to the onset of the next interval.

In adults, an omnibus ANOVA revealed a significant interaction between time window and trial type (Critical vs. Control), $F 1(7,175)=2.96, p=.006, \eta^{2}=.11 ; F 2(7,105)=2.06, p=.05, \eta^{2}=.12$. Follow-up analyses revealed that fixations to the Competitor were greater than the Control in the $300 \mathrm{~ms}\left(\mathrm{~F} 1(1,24)=4.89, \mathrm{p}=.03, \eta^{2}=.19 ; \mathrm{F} 2(1,15)=4.23, \mathrm{p}=.06, \eta^{2}=.22\right)$ and $400 \mathrm{~ms}$ time windows $\left(\mathrm{F} 1(1,24)=4.54, \mathrm{p}=.04, \eta^{2}=.18 ; \mathrm{F} 2(1,15)=3.25, \mathrm{p}=.09, \eta^{2}=.18\right){ }^{2}$ Like Yee and Sedivy $(2006)$, we found evidence of a short-lived activation of the phono-semantic competitor that was timelocked to the initial ambiguity between the Target and the mediating phonological associate. A parallel ANOVA on children's fixations also revealed a significant interaction between time window and trial type, $F 1(7,203)=2.41, p=.02, \eta^{2}=.08 ; F 2(7,105)=1.59 p=.15, \eta^{2}=.10$. Follow-up analyses revealed that fixations to the Competitor were greater than the Control from the $200 \mathrm{~ms}$ $\left(\mathrm{F} 1(1,28)=3.98, \mathrm{p}=.05, \eta^{2}=.13 ; \mathrm{F} 2(1,15)=2.87, \mathrm{p}=.11, \eta^{2}=.16\right)$ through $600 \mathrm{~ms}$ time windows $\left(\mathrm{F} 1(1,28)=4.45, \mathrm{p}=.04, \eta^{2}=.13 ; \mathrm{F} 2(1,15)=3.88, \mathrm{p}=.07, \eta^{2}=.21\right)$. Thus children, like adults, demonstrated a period of semantic priming from a phonological competitor. In children however, this priming persisted $200 \mathrm{~ms}$ beyond the point where the mediating phonological associate was disambiguated from the Target.

\footnotetext{
${ }^{2}$ Due to the relatively small number of items used, many effects that were robust in the subjects analysis failed to reach conventional levels of significance in the items analysis.
} 
We compared the degree of priming in these two groups by analyzing the mean proportion of looks to the Competitor/Control pictures in an ANOVA with trial type (Critical vs. Control) as a within-subjects variable and age (Adult vs. Child) as a between-subjects variable. We focus on the region of significant priming in children (200-600ms window) to determine whether priming in this group differed significantly from the priming seen in adults. Figure 5 illustrates that looks to the Competitor were significantly greater than those to the Control picture among both adults $(20 \%$ vs. $14 \%)$ and children $(23 \%$ vs. $15 \%), F 1(1,54)=12.86, p=.001, \eta^{2}=.19 ; F 2(1,30)=9.24$, $\mathrm{p}=.005, \eta^{2}=.24$. However, there were no effect of age or interaction between age and trial type (all p's $>.20$ ), suggesting that children exhibited the same degree of phono-semantic priming as adults.

\section{INSERT FIGURE 5 HERE}

Surprisingly, the children's actions provided additional insight into the development of lexical processing. While adults made no errors in this task, children mistakenly selected a nonTarget picture in $4 \%$ of all trials. Figure 6 illustrates that while children were equally likely to select a Distractor object in the two trial types ( $p$ 's $>.80$, Fisher's exact test), they were far more likely to mistakenly select the Competitor on critical trials than they were to select the matched Control item on control trials ( $\mathrm{p}=.01$, Fisher's exact test). This suggests that children were sometimes unable to inhibit the activation of the phono-semantic prime. Altogether, our findings suggest that early lexical processing involves cascading activation across levels of representation: Partial phonological activation of word forms is propagated up to the semantic level resulting in eye movements to (and sometimes selection of ) semantic associates.

INSERT FIGURE 6 HERE 
Finally, perusal of Figures 3 and 4 suggests one potential limitation of these data. While the significant preference for the Competitor over the Control item did not appear until after the onset of the critical word, there was a small, nonsignificant difference between the two that emerged towards the end of the baseline period. These early looks to the Competitor could reflect processing of the word based on co-articulatory information. Because we did not splice the instructions, participants may have had access to relevant acoustic information prior to the first $100 \mathrm{~ms}$ time window. Alternately, this could reflect differences in visual salience. While we attempted to control for salience by using the same pictures as Competitors and Controls, the salience of an item in context, presumably depends on the other items in the scene which were necessarily different across the two trial types. Finally it could simply be noise.

To explore whether the preference for the Competitor could be due to perceptual biases of this kind, we conducted two additional analyses. First, we compared changes in the proportion of looks to the Competitor/Control pictures in critical and control trials during two time periods of interest: the baseline period prior to the onset of the target word ('Pick up the') and the critical windows associated with the phono-semantic priming (300-400ms window in adults and 200$600 \mathrm{~ms}$ window in children). We found marginal interactions between trial type and time period in both adults $\left(\mathrm{F} 1(1,25)=3.05, \mathrm{p}=.09, \eta^{2}=.11 ; \mathrm{F} 2(1,15)=2.30, \mathrm{p}=.15, \eta^{2}=.13\right)$ and children $\left(\mathrm{F} 1(1,29)=3.21, \mathrm{p}=.08, \eta^{2}=.10 ; \mathrm{F} 2(1,15)=1.87, \mathrm{p}=.19, \eta^{2}=.11\right)$, suggesting that the onset of the target word was followed by an increased preference for the Competitor. Second, we examined a subset of items in which looks to the Competitor and Control item were matched prior to the onset of the critical word ( 8 out of 16 items). In adults, looks to Competitor were no different than those to the Control item during the baseline period ( $29 \%$ vs. $29 \%$; p > 90 ), but during the critical window, looks to the Competitor exceeded those to the Control item (34\% vs. $17 \%$; 
$\left.\mathrm{F} 1(1,25)=8.39, \mathrm{p}=.01, \eta^{2}=.25\right)$. A similar pattern emerged in children where looks to Competitor and Control item were no different during the baseline period ( $28 \%$ vs. $29 \%$ respectively; $\mathrm{p}>.90)$ but during the critical window, looks to the Competitor exceeded those to the Control item (26\% vs. $\left.16 \% ; \mathrm{F} 1(1,29)=19.14, \mathrm{p}=.001, \eta^{2}=.31\right)$.

However, another way to definitively distinguish whether looks to the Competitor truly reflect lexical access of the Target is to use the same displays but modify the instructions to ask for an unrelated picture (e.g., 'Pick up the shirt'). If prior preference for the Competitor is not specifically linked to linguistic processing, then we should again expect to find greater fixations to the Competitor. If however, this preference reflects phono-semantic priming, then looks to the Competitor should no longer differ from the Control.

\section{Experiment 2}

\subsection{Methods}

Twenty-six undergraduate students and 30 five-year-olds (ranging from 5;1 to 5;6, mean age 5;3) participated in this study. All participants were native English speakers.

\subsubsection{Procedure and Materials}

The procedure and materials were identical to Experiment 1 but the target utterance now asked for a Distractor, e.g., 'Pick up the shirt.' We will now refer to this picture as the Target but will continue to refer to the pictures of interest as the Competitor and Control items. The data was coded in the manner described in Experiment 1. Twenty-five percent of trials were double coded and inter-coder reliability was $95.6 \%$.

\subsection{Results and Discussion}

Figures 7 and 8 illustrate that Target looks for both adults and children again began around chance prior to the onset of the critical word and rapidly increased following this target word. 
As in Experiment 1, we found no difference in the proportion of looks to the Competitor and Control picture prior to the onset of the target word in both adults ( $22 \%$ vs. $23 \%)$ or children, ( $27 \%$ vs. $29 \%$; all p's $>.50$ ). We then calculated the proportion of Competitor and Control fixations for $100 \mathrm{~ms}$ intervals beginning from the onset of the target word and continuing until 1000ms later. However unlike in Experiment 1, an omnibus ANOVA here revealed no significant interaction between time window and trial type (Control vs. Critical) in both adults and children (all p's $>.50$ ). A closer examination of the fine-grained time windows also revealed no effect of trial type in each of the individual intervals (all p's $>.20$ ).

Next we focused on Competitor/Control looks during the significant priming windows established in Experiment 1 (300-400ms window in adults and 200-600ms window in children). Using an ANOVA, we compared how looks to these items varied with respect to trial type (Critical vs. Control) as a within-subjects variable and Experiment (1 vs. 2) as a betweensubjects variable. Both adults $\left(\mathrm{F} 1(1,50)=6.61, \mathrm{p}=.01, \eta^{2}=.12 ; \mathrm{F} 2(1,30)=3.77, \mathrm{p}=.06, \eta^{2}=.11\right)$ and children $\left(\mathrm{F} 1(1,58)=5.86, \mathrm{p}=.02, \eta^{2}=.10 ; \mathrm{F} 2(1,30)=5.25, \mathrm{p}=.03, \eta^{2}=.15\right)$ demonstrated the predicted interaction between trial type and Experiment. This suggests that looks to the Competitor were only greater than looks to the Control item in situations where the Competitor was semantically related to a phonological associate of the spoken target word.

\section{INSERT FIGURES $7 \& 8$ HERE}

Finally, as in Experiment 1, adults never made errors their actions in this task. In contrast, children also made fewer incorrect selections compared to Experiment 1 (4\% vs. 1\% of all trials, $\mathrm{Z}=2.05, \mathrm{p}=.04)$. Critically, the frequency of errors in Experiment 2 did not differ across selection of the Competitor and Control items ( $\mathrm{p}>$.40, Fisher's exact test). Focusing in just on the Critical trials, we found a greater preference to select the Competitor in Experiment 1 
compared to Experiment 2 ( $\mathrm{p}=.02$, Fisher's exact test). This suggests that children's errors were driven by their failure to inhibit the activation of the phono-semantic prime.

\section{General Discussion}

This study demonstrates the presence of informational cascade in early word recognition. Like adults, children map partial speech input onto phonological representation which in turn activate candidate lexical entries and their semantic representations. These findings provide converging evidence that the ability to incrementally process information across multiple levels of representation is a basic architectural feature of the lexicon (Swingley et al., 1999; Fernald et al., 2001; Sekerina \& Brooks, 2007). However, our results also point to a possible difference between the two age groups. Unlike adults, children continue to look at the phono-semantic prime even after the ambiguity between the referent and the mediating phonological associate had been resolved. Furthermore, children were more likely to mistakenly select this prime relative to an unrelated item. Thus while adults are able to use rapidly use subsequent phonological information to swiftly rule out the phono-semantic competitor, children sometimes fail to do so.

This suggests the possibility that children are less adept at resolving the competition between the target and phono-semantic prime. Evidence of parallel difficulties in over-riding an initial misinterpretation occur in a variety of linguistic domains ranging from syntactic ambiguity resolution (Trueswell et al., 1999; Snedeker \& Trueswell, 2004), to homonym interpretation (Mazzocco, 1997; Doherty, 2004), and pragmatic inferencing (Huang \& Snedeker, in press). For example, Trueswell and his colleagues (1999) presented adults and five-year-olds with temporarily ambiguous sentence like 'Put the frog on the napkin in the box.' When the sentences were presented in contexts with just one frog, both adults and children initially 
misinterpreted the first prepositional phrase as a location. However, when adults heard the disambiguating phrase ('in the box'), they quickly reinterpreted the first prepositional phrase ('on the napkin') as a modifier of the noun. Children however continued to interpret this ambiguous phrase as a goal and performed actions that reflected this misanalysis.

Novick and colleagues have suggested that children's inability to revise despite the presence of incongruent linguistic cues may be due in part to the immaturity of cognitive control mechanisms at this age (Novick, Trueswell, \& Thompson-Schill, 2005). Cognitive control, it is argued, is necessary for any task in which one must reconcile conflicting information or revise or override a preferred analysis. These abilities continue to develop throughout middle childhood, as evidenced by children's poor performance on measures such as the Stroop task, the go/no-go task (Bunge, Dudukovic, Thomason, Vaidya, \& Gabrieli, 2002), delayed-response tasks (Diamond \& Doar, 1989), and tasks of selective attention (Luciana \& Nelson, 1998; Pearson \& Lane, 1991). This would also be in line with a recent study demonstrating that children's ability to inhibit a default interpretation during language comprehension is related to their performance on a Dimensional Change Card Sorting task (Jincho, Mazuka, \& Yamane, 2007).

However, while the cognitive control hypothesis seeks explanations for children's linguistic behavior by examining co-occurring changes across multiple domains, an alternate strategy is to closely examine the process of word recognition itself in search of mechanisms which might account for the observed differences between the adults and children. Two possibilities come to mind. First, the more persistent activation of the phono-semantic prime in the children could reflect slower or less efficient processing of the incoming phonological information. This could result in a weaker advantage for the target word-form relative to the absent cohort competitor, and thus might lead to continued interference from the phono-semantic 
competitor. Our results provide some support for this hypothesis. In the first $100 \mathrm{~ms}$ window following the onset of the target word, adults' average looks to the Target exceeded those of children in both Experiment $1\left(36 \%\right.$ vs. $27 \%$; F1(1,54)=3.91,p=.05, $\eta^{2}=.09 ; \mathrm{F} 2(1,30)=$ $\left.3.10, \mathrm{p}=.09, \eta^{2}=.09\right)$ and Experiment $2\left(38 \%\right.$ vs. $28 \% ; \mathrm{F} 1(1,54)=11.33, \mathrm{p}=.001, \eta^{2}=.17 ; \mathrm{F} 2(1,30)=$ $\left.7.88, \mathrm{p}=.009, \eta^{2}=.21\right)$. This latter difference is particularly informative since it suggests that children's delays were not driven solely by the semantic priming of the Competitor but instead might reflect the reduced efficiency of bottom-up activation from the speech signal. This hypothesis also provides an alternate account for recent findings demonstrating extended phonological cohort competition in children at this age (e.g., looks to a lock after hearing $\log$, Sekerina \& Brooks, 2007).

Second, the children's failure could reflect the immaturity of a mechanism which inhibits competing representations. Such mechanisms are a common feature of current models of adult word recognition. For example, the TRACE model (McClelland \& Elman, 1986) includes both excitatory connections between phonological and lexical units as well as inhibitory connections between units at the same level. These latter connections serve an important role in resolving competition among active candidate forms yet they do so through a much more bottom-up process: inhibition of one node is a passive result of activation of some other node. Thus, on this account, a developmental change in the inhibition of lexical competitors would be captured by increasing the strength of these local inhibitory connections over time. Such a proposal seems quite different in spirit than one invoking the development of a central control process.

These experiments suggest several lines of inquiry. First, they raise the question of whether there are early individual differences in the processes underlying word recognition and whether these differences have implications on later development. Recent developmental work 
suggests that there are robust individual differences in the speed of word recognition in infancy which predict differences in linguistic and cognitive abilities throughout early childhood (Fernald, Perfors, \& Marchman, 2006; Marchman \& Fernald, 2008). Work on adult word recognition has also highlighted individual differences in frequency and cohort effects which in turn influence the speed of lexical processing (Mirman, Dixon, \& Magnuson, 2008). Second these results raise the question of whether incremental propagation is present at even earlier stages of lexical development. We are currently using this procedure to examine word recognition in three-year-olds. Evidence of phono-semantic priming in this age would provide further support for the hypothesis that incremental propagation is a basic architectural feature of the lexicon that is present early in development. 


\section{References}

Allopenna, P. D., Magnuson, J. S., \& Tanenhaus, M. K. (1998). Tracking the time course of spoken word recognition using eye movements: Evidence for continuous mapping models. Journal of Memory and Language, 38, 419-439.

Bunge, S. A., Dudukovic, N. M., Thomason, M. E., Vaidya, C. J., \& Gabrieli, J. D. (2002). Immature frontal lobe contributions to cognitive control in children: Evidence from fMRI. Neuron, 33, 1-11.

Dell, G. S., Schwartz, M. F., Martin, N., Saffran, E. M., \& Gagnon, D. A. (1997). Lexical access in aphasic and nonaphasic speakers. Psychological Review, 104, 801-838.

Dempster, F. N. (1981). Memory span: Sources of individual and developmental differences. Psychological Bulletin, 89, 63-100.

Diamond, A. \& Doar, B. (1989). The performance of human infants on a measure of frontal cortex function, the delayed response task. Developmental Psychobiology, 22, 271-294.

Doherty, M. J. (2004). Children's difficulty in learning homonyms. Journal of Child Language, $31,203-214$.

Flavell, J. H. (1986). The development of children's knowledge about the appearance-reality distinction. American Psychologist, 41, 418-425.

Fernald, A., Swingley, D., \& Pinto, J.P. (2001). When half a word is enough: Infants can recognize spoken words using partial phonetic information. Child Development, 72, 1003-1015.

Fernald, A., Perfors, A., \& Marchman, V.A. (2006). Picking up speed in understanding: speech processing efficiency and vocabulary growth across the 2nd year, Developmental Psychology, 42 (1), 98-116. 
Hughes, C. \& Graham, A. (2002). Measuring executive functions in childhood: Problems and solutions? Child \& Adolescent Mental Health, 7(3), 131-142.

Jincho, N., Mazuka, R., \& Yamane, N. (2007). 'No, there is no cat in the second place!': Children's incremental processing of prenominal modifiers and executive control of response inhibition. Proceedings of the 20th Annual CUNY Conference on Sentence Processing, La Jolla, CA.

Joseph, H. S. S. L., Liversedge, S. P., Blythe, H. I., White, S. J., Gathercole, S. E., \& Rayner, K. (2007). Children's and adults' processing of anomaly and implausibility during reading: Evidence from eye movements. The Quarterly Journal of Experimental Psychology, 61, 708-723.

Kail, R.V. (1991). Development of processing speed in childhood and adolescence. In H. W. Reese (Ed.), Advances in child development and behavior (Vol. 25). New York: Academic Press.

Kail, R.V. \& Salthouse, T.A. (1994). Processing speed as a mental capacity. Acta Psychologica, $86,199-225$.

Luciana, M., \& Nelson, C. A. (1998). The functional emergence of prefrontally guided working memory systems in four- to eight-year-old children. Neuropsychologia, 36, 273-293.

MacDonald, M., Pearlmutter, N. \& Seidenberg, M. (1994). The lexical nature of syntactic ambiguity resolution. Psychological Review, 101, 676-703.

Marchman, V.A. \& Fernald, A. (2008). Speed of word recognition and vocabulary knowledge in infancy predict cognitive and language outcomes in later childhood. Developmental Science, 11, F9 - F16.

Marslen-Wilson, W.D. (1987). Functional parallelism in spoken word-recognition. Cognition, 
$25,71-102$.

Matin, E., Shao, K. \& Boff, K. (1993). Saccadic overhead: information processing time with and without saccades. Perception \& Psychophysics, 53(4), 372-380.

Mazzocco, M. (1997). Children's interpretations of homonyms: A developmental study. Journal of Child Language, 24, 441-467.

McClelland, J. L. \& Elman, J. L. (1986). The TRACE model of speech perception. Cognitive Psychology, 18, 1-86.

Mirman, D., Dixon, J.A., \& Magnuson, J.S. (2008). Statistical and computational models of the visual world paradigm: Growth curves and individual differences. Journal of Memory and Language, 59(4), 475-494.

Nelson, D. L., McEvoy, C. L., \& Schreiber, T. A. (1998). The University of South Florida word association, rhyme, and word fragment norms. http://www.usf.edu/FreeAssociation/.

Novick, J.M., Trueswell, J.C., \& Thompson-Schill, S.L. (2005). Cognitive control and parsing: Re-examining the role of Broca's area in sentence comprehension. Journal of Cognitive, Affective, and Behavioral Neuroscience, 5(3), 263-281.

Passler M.A., Isaac W., Hynd G.D. (1985). Neuropsychological development of behavior attributed to frontal lobe functioning in children. Developmental Neuropsychology, 1: $349-370$.

Permer, J. \& Wimmer, H. (1985). "John thinks that Mary thinks that . . .": Attribution of secondorder beliefs by 5- to 10-year-old children. Journal of Experimental Child Psychology. $39,437-471$.

Piaget, J. (1946). The development of children's concept of time. Paris: Presses Universitaires de France. 
Schneider, W., \& Bjorklund, D. F. (1998). Memory. In D. Kuhn \& R. S. Siegler (Eds.), Cognitive, language, and perceptual development, Vol. 2 (pp. 467-521). In W. Damon (General Editor), Handbook of child psychology (5th Ed.). New York: Wiley.

Sekerina, I. A., \& Brooks, P. J. (2007). Eye movements during spoken word recognition in Russian children. Journal of Experimental Child Psychology, 98, 20 - 45.

Snedeker, J. \& Trueswell, J. (2004). The developing constraints on parsing decisions: The role of lexical biases and referential scenes in child and adult sentence processing. Cognitive Psychology, 49, 238-299.

Swingley, D., Pinto, J.P., and Fernald, A. (1999). Continuous processing in word recognition at 24 months. Cognition, 71, 73-108.

Traxler, M. J. (2002). Plausibility and subcategorization preference in children's processing of temporarily ambiguous sentences: Evidence from self-paced reading. The Quarterly Journal of Experimental Psychology, 55, 75-96.

Trueswell, J. \& Tanenhaus, M. (1994). Toward a lexicalist framework of constraint-based syntactic ambiguity resolution. In Clifton and Frazier (Eds), Perspectives on sentence processing. Hillsdale, NJ: Lawrence Erlbaum.

Trueswell, J.C., Sekerina, I., Hill, N.M. \& Logrip, M.L. (1999). The kindergartenpath effect: studying on-line sentence processing in young children. Cognition, 73, 89-134.

Welsh, M., Pennington, B., \& Groisser, D. (1991). A normative-developmental study of executive function: A window on prefrontal function in children. Developmental Neuropsychology. 7, 131-149. 
Huang, Y. \& Snedeker, J. (in press). Semantic meaning and pragmatic interpretation in fiveyear-olds: Evidence from real time spoken language comprehension. To appear in Developmental Psychology.

Yee, E., \& Sedivy, J. (2006). Eye movements to pictures reveal transient semantic activation during spoken word recognition. Journal of Experimental Psychology: Learning, Memory, \& Cognition, 32, 1-14. 